\title{
Pattern of Pain and its Interference on Activities of Daily Life among Older Adults in Bharatpur Municipality, Chitwan, Nepal
}

\section{Shankar Nand Subedi*}

Department of Community Medicine and Public Health, Tribhuvan University, Maharajgunj Medical Campus, Kathmandu, Nepal

\begin{abstract}
Background: Pain is a most common condition in the older population, and the presence of pain in later life may have detrimental and deteriorative effect on their daily activities. The present study is conducted to assess the pattern of pain among the older adults and its interference on their daily activities.

Methods: In this cross-sectional descriptive study, a total of 150 community dwelling older people aged 60 years and above were included from Bharatpur municipality of Chitwan district. Data include sociodemographic characteristics, pain pattern, its severity and impact. The pain intensity and degree to which pain interfered with daily activities of older people in the preceding one week was measured by using Brief Pain Inventory (BPI) on 0-10 numeric rating scale.

Results: The prevalence of physical pain among the older adults was found $40.7 \%$ with median age of 66 years (IQR: 62-72 years) and presence of pain was mainly associated with their predominant diseases or injuries. Burning type of pain was mostly apparent in this group and majorities were complaining pain in their legs having joint problem. In the preceding one week, the mean intensity of pain at its worst time was found severe $(6.67 \pm 1.85)$. There was a highest interference of pain on sleep $(r=0.621, p<0.001)$ of elderly population. Also, significant but moderate positive impact of pain at its worst was on enjoyment of life $(r=0.463, p<0.001)$ and $\operatorname{mood}(r=0.377, p=0.003)$ of the elderly people.
\end{abstract}

Conclusion: The findings of this study indicate the need for better programmatic efforts including psychological consultation and multidimensional pain assessment in this population.

Keywords: Pain; Interference; Older adults; Daily activities

\section{Introduction}

A major shift in the age distribution of the world's population is now taking place. The geriatric population is increasing rapidly, due to a significant decline in the number of births, advancement in medical treatment and technology, eradication of many infectious diseases, and improved nutrition, hygiene and sanitation. With the rapidly increasing ageing population in developing countries, care of the elderly is creating challenges that will be exacerbated in the future. At present the majority of older people in developing countries are cared for by their families. Similarly, with advancing age, physical, psychological, social which leading spiritual changes occur resulting in an increase of chronic diseases, which leads to dependency of older people too. Life expectancy at birth of the population of both sexes in SEAR countries is increasing in almost every country [1]. Population ageing is pervasive since it is affecting nearly all the countries of the world. Nepal is also witnessing the expansion of life span and hence an enhancement in the population of the elderly [2]. In Nepal, individuals over 60 years of age are considered elderly [3]. There were 2.15 million elderly people constituting $8.14 \%$ of the total population according to National Census Report 2011. Ageing population is increasing in Nepal by $4.3 \%$ per annum while the total population growth rate is 1.35 per annum only $[3,4]$.

Pain is a very common problem for older persons, with extensive variation in prevalence rates from $25 \%$ to $90 \%$, living in the community setting [5-8]. They have lived longer and have a greater chance of developing degenerative and pathological conditions. Age frequently carries the burden of disease many of which turn are associated with pain and discomfort, as well as various other disabilities [9]. Also, older persons are more vulnerable than younger persons since they often suffer from multiple medical and nutritional problems, which limit treatment options with analgesic agents, due to an increased risk of adverse effects and problems with complex drug interactions [10]. There are particular reasons for paying attention to the chronic pain among older people living in the community. They have limited assess of care from their families and inadequately covered economic and health security measures. They may have poor socio-economic status. Their pain is generally unrecognized and untreated because of misconception that the elderly feel less pain, unwilling to complain, age related stoicism, and elderly family members are getting less priority for the treatment. Such a pain can cause unnecessary suffering like anorexia, weight loss, weakness, nausea, pressure sores, insomnia, depression, anxiety and even suicide risk and poses a substantial burden to individual, their family and society. In addition to these myriad physiological consequences, pain also impair in the general activities of daily life as well as on mood, walking ability, normal work, relationship with others, sleep and enjoyment of life $[11,12]$. Good pain management for the elderly people can be planned with the help of self-reported pain assessment so their activities and later life can be comfortable and meaningful. Therefore, this study was undertaken to assess the pattern of pain and its interference on daily activities among elderly people.

*Corresponding author: Shankar Nand Subedi, Department of Community Medicine and Public Health, Tribhuvan University, Maharajgunj Medical Campus, Kathmandu, Nepal, Tel: 977-9845397575; Email: shankarsbd@iom.edu.np

Received August 21, 2017; Accepted August 31, 2017; Published September 04, 2017

Citation: Subedi SN (2017) Pattern of Pain and its Interference on Activities of Daily Life among Older Adults in Bharatpur Municipality, Chitwan, Nepal. J Geronto Geriatr Res 6: 445. doi:10.4172/2167-7182.1000445

Copyright: (c) 2017 Subedi SN. This is an open-access article distributed under the terms of the Creative Commons Attribution License, which permits unrestricted use, distribution, and reproduction in any medium, provided the original author and source are credited. 


\section{Materials and Methods}

\section{Study settings}

This community based cross-sectional study was conducted among older population in Bharatpur Municipality of Chitwan district of Nepal and the participants were recruited using multi stage random sampling method. Our inclusion criteria were older adults (both men and women) aged 60 years and above. Bed ridden elderly, had surgery within the past six months and who is blind, cannot speak and hear properly were excluded from the study. The district was selected from center of Nepal by geographical recognizance and the municipality was randomly selected from out of 38 VDCs and municipalities. Five wards were chosen randomly for the recruitment of the participants. The sample size determined for this study was 150 and the participants were selected proportionately from these five wards. To minimize the bias in sample selection, the first respondent to be visited in each ward was selected randomly from the middle part of the ward by using ward map. After visiting the first household, the second household to be visited was the one that is nearest to the first. The nearest household was defined as the household reachable in the shortest time on foot from the household just visited. If there were two or more households equally near to the one just visited, selected the one on the immediate right as interviewer stands in the doorway of the house looking out. In cases where the household had no eligible elderly person or absent at the time of visit, the interviewer moved to the next household and these steps continued till required sample reached from each ward. If there were more than one eligible participant in a house, the senior most one was the study participant. Face to face interviews were conducted by using a semi structured interview schedule after taking verbal consent from the respondents. The ethical approval for this study was obtained from the Institutional Ethics Committee and the necessary permission was obtained from the corresponding municipality for the data collection.

\section{Measures}

Semi structured questionnaire along with Brief Pain Inventory (BPI) tool in local language was used to collect the information from the participants. The pain intensity and pain interference were measured by using numeric pain rating scale which has been validated and used in populations that included older adults with multiple pain types and across multiple countries and cultures for clinical pain assessments, epidemiological studies and in studies on the effectiveness of pain treatment. Pain intensity were measured by using 0 -10-point numeric scale anchored by 0 representing "no pain" and 10 being "extreme pain" for the last week. Similarly, to measure how much was the interferences by pain during the preceding week to the general activities, mood, walking, normal work, relationships with others, sleep and enjoyment of life, same 0-10-point scale was used, where 0 represents "Does not interfere" and 10 denotes "completely interferes" [13].

\section{Statistical analysis}

Descriptive statistics were used to describe the sample characteristics in terms of demographic and pain-related variables. Chi-square test was done to test the association between variables. Odds ratio was used to compare the characteristics of the participants with and without pain through binary logistic regression. Spearman's Rank Correlation coefficient was used to explore the relationship between pain intensity and pain interference. All significance levels were set at 5\% and 95\% CI. Data analysis were done by using IBM SPSS statistics version 20.0.

\section{Results}

A total of 150 older people having age 60 years and above (median age 66 years, range $60-84$ years, $53.3 \%$ male) were included in this study. Among them, 70.7\% were living married life with their partners and $44 \%$ participants were illiterate. Most of the participants belonged to joint family and living with the family members consisting of more than 5 persons in the family. The prevalence of physical pain was $40.7 \%$ in our sample. Majority of the participants having pain were in the age group of $60-69$ years $(70.5 \%)$ and it tends to be decreased $(\mathrm{OR}=0.3, \mathrm{CI}=0.13-0.70)$ after seventies and up to eighties. Although male demonstrated higher incidence of pain $(54.1 \%)$ than females (45.9\%), however no significant association was found between gender and the pain incidence. Pain appeared to be high among elders who were illiterate, living with spouse, having extended family and relatively smaller size, but the association was not found statistically significant at 95\% CI. But the presence of diseases $(\mathrm{OR}=2.44, \mathrm{CI}=1.25-4.76)$ and or injuries $(\mathrm{OR}=2.45, \mathrm{CI}=1.09-5.47)$ in their life were found significantly associated with pain prevalence. In our study, $52.2 \%$ of the elders having pain were suffering from any kind of diseases and $58.1 \%$ had met some kinds of accident or injuries in their life span (Table 1).

In our study, older adults with physical pain were asked to report severity of pain and its nature in the preceding one week. Among the older people having pain, more than half $(54.1 \%)$ reported they had moderate pain when it was worst, $31.2 \%$ expressed it was severe, $13.1 \%$ reported extreme and, only $1.6 \%$ ranked for mild type pain. The mean intensity of pain at its worst was found $6.67 \pm 1.85$ indicating severe type pain was prevalent in these populations when it was worst.

\begin{tabular}{|c|c|c|c|c|}
\hline \multirow{2}{*}{ Variables } & \multirow{2}{*}{$\begin{array}{l}\text { Total } \\
\text { n (\%) }\end{array}$} & \multicolumn{2}{|c|}{ Pain } & \multirow{2}{*}{ OR $(95 \% \mathrm{Cl})$} \\
\hline & & Presence & Absence & \\
\hline Overall & $150(100)$ & $61(40.7)$ & $89(59.3)$ & $(32.84-48.56)$ \\
\hline \multicolumn{5}{|c|}{ Age (years) } \\
\hline $60-69$ & $92(61.3)$ & $43(46.7)$ & $49(53.3)$ & 1 \\
\hline $70-79$ & $43(28.7)$ & $9(20.9)$ & $34(79.1)$ & $0.30(0.13-0.70)$ \\
\hline 80 and more & $15(10)$ & $9(60)$ & $6(40)$ & $1.70(0.56-5.19)$ \\
\hline \multicolumn{5}{|c|}{ Median age: 66 years, IQR: $62-72$ years, Min: 60 yrs, Max: 84 yrs } \\
\hline \multicolumn{5}{|c|}{ Gender } \\
\hline Male & $80(53.3)$ & $33(41.2)$ & $47(58.8)$ & 1 \\
\hline Female & $70(46.7)$ & $28(40)$ & $42(60)$ & $0.95(0.49-1.82)$ \\
\hline \multicolumn{5}{|c|}{ Marital status } \\
\hline Single & $44(29.3)$ & $16(36.4)$ & $28(63.6)$ & 1 \\
\hline Living with spouse & $106(70.7)$ & $45(42.5)$ & $61(57.5)$ & $\begin{array}{l}\text { 1. } 29(0.62- \\
2.66)\end{array}$ \\
\hline \multicolumn{5}{|c|}{ Education level } \\
\hline Literate & $84(56)$ & $32(38.1)$ & $52(61.9)$ & 1 \\
\hline Illiterate & $66(44)$ & $29(43.9)$ & $37(56.1)$ & $1.27(0.66-2.45)$ \\
\hline \multicolumn{5}{|c|}{ Occupational status } \\
\hline Farming & $46(30.7)$ & $18(39.1)$ & $28(60.9)$ & 1 \\
\hline Others & $104(69.3)$ & $43(41.3)$ & $61(58.7)$ & $1.09(0.54-2.23)$ \\
\hline \multicolumn{5}{|c|}{ Type of family } \\
\hline Joint & $65(43.3)$ & $29(44.6)$ & $36(55.4)$ & 1 \\
\hline Extended & $85(56.7)$ & $32(37.6)$ & $53(62.4)$ & $0.81(0.23-2.78)$ \\
\hline \multicolumn{5}{|c|}{ Size of family } \\
\hline$\leq 5$ person & $11(7.3)$ & $7(63.6)$ & $4(36.4)$ & 1 \\
\hline$>5$ person & $139(92.7)$ & $54(38.8)$ & $85(61.2)$ & $0.36(0.10-1.29)$ \\
\hline \multicolumn{5}{|c|}{ Presence of any disease } \\
\hline No & $81(54)$ & $25(30.9)$ & $56(69.1)$ & 1 \\
\hline Yes & $69(46)$ & $36(52.2)$ & $33(47.8)$ & $2.44(1.25-4.76)$ \\
\hline \multicolumn{5}{|c|}{ Any injury met in life } \\
\hline No & $119(79.3)$ & $43(36.1)$ & $76(63.9)$ & 1 \\
\hline Yes & $31(20.7)$ & $18(58.1)$ & $13(41.9)$ & $2.45(1.09-5.47)$ \\
\hline
\end{tabular}

Table 1: General characteristics of the participants and their association with pain $(n=150)$. 
Majority of the participants reported they experience severe pain generally at evening $(32.8 \%)$ and night $(37.7 \%)$ time. Twenty three percent elderly expressed their pain as burning in nature followed by $19.6 \%$ as cramping, $16.4 \%$ as dull, $13.1 \%$ as sharp, $11.5 \%$ as prickling, $9.8 \%$ as aching and $6.6 \%$ expressed aching. In this sample, most of the male respondents reported burning type pain while most of the women expressed cramping type pain. Regarding the site of pain, $32.8 \%$ reported they had pain in their legs having especially joint problem followed by pain in waist region. Among the elderly participants having

\begin{tabular}{|c|c|c|}
\hline Variables & Frequency & Percent \\
\hline \multicolumn{3}{|c|}{ Severity of pain at its worst } \\
\hline Mild (1-3) & 1 & 1.6 \\
\hline Moderate (4-6) & 33 & 54.1 \\
\hline Severe (7-9) & 19 & 31.2 \\
\hline Extreme (10) & 8 & 13.1 \\
\hline \multicolumn{3}{|c|}{ Mean intensity (mean, SD, range): $6.67 \pm 1.85(0-10)$} \\
\hline \multicolumn{3}{|c|}{ Time of pain at its worst } \\
\hline Morning & 8 & 13.1 \\
\hline Day & 10 & 16.4 \\
\hline Evening & 20 & 32.8 \\
\hline Night & 23 & 37.7 \\
\hline \multicolumn{3}{|c|}{ Nature of pain } \\
\hline Dull & 10 & 16.4 \\
\hline Sharp & 8 & 13.1 \\
\hline Cramping & 12 & 19.6 \\
\hline Burning & 14 & 23.0 \\
\hline Prickling & 7 & 11.5 \\
\hline Throbbing & 4 & 6.6 \\
\hline Aching & 6 & 9.8 \\
\hline \multicolumn{3}{|c|}{ Sites of pain* } \\
\hline Head & 4 & 6.6 \\
\hline Mouth & 4 & 6.6 \\
\hline Neck/Shoulder & 4 & 6.6 \\
\hline Chest & 5 & 8.2 \\
\hline Abdomen & 7 & 11.5 \\
\hline Spine/Waist & 9 & 14.8 \\
\hline Hand (s) & 8 & 13.1 \\
\hline $\operatorname{Leg}(\mathrm{s})$ & 20 & 32.8 \\
\hline \multicolumn{3}{|c|}{ Duration of pain } \\
\hline Less than 1 year & 7 & 11.5 \\
\hline $1-5$ years & 27 & 44.2 \\
\hline $6-10$ years & 13 & 21.3 \\
\hline More than 10 years & 14 & 23.0 \\
\hline \multicolumn{3}{|c|}{ Perceived underlying cause of pain } \\
\hline Diseases & 14 & 22.9 \\
\hline Injuries & 6 & 0.1 \\
\hline Unknown & 41 & 67.2 \\
\hline
\end{tabular}

Table 2: Pattern of pain among participants $(n=61)$. pain, $49.18 \%$ had presence of any kind of disease(s) and $21.31 \%$ had met any type of accidents or injuries during their lifespan (Table 2).

Table 3 shows the distribution of respondents by level of interference due to their pain on daily activities of the elderly population. The greatest interference by pain was found on mood (3.44 \pm 2.76$)$ and sleep $(3.08 \pm 2.6)$ of the elder people, but slight interference was found on other activities such as walking ability $(2.08 \pm 2.11)$, general activities (1.59 \pm 2.16$)$, enjoyment of life $(0.79 \pm 1.75)$, normal work $(0.64 \pm 1.28)$ and relations with others $(0.39 \pm 1.04)$. The overall mean interference of pain on activities of elderly people in this study was found $1.71 \pm$ 1.21. There was strong positive correlation between pain and sleep $(\mathrm{r}=0.621, \mathrm{p}<0.001)$. Moderate positive interference of pain was found on enjoyment of life $(r=0.463, p<0.001)$ and $\operatorname{mood}(r=0.377, p=0.003)$ of the elderly people.

\section{Discussion}

In this community based cross-sectional study, the prevalence of pain among older people was found $40.7 \%$. Majority (70.5\%) of the participants having pain were in the age group of 60-69 years and mostly prevalent in men (54.1\%). Age was found significant factor in pain prevalence. After comparing results of current study with previous studies, it was found that the prevalence of chronic pain in this study is lower than that reported by Ferrell et al. (51\%) [5] and Lansbury (84\%) [14], but consistent with Crook et al. (40\%) [7], Yu HY et. al. 2004 (42\%) [15] and Francesco et al. (44\%) [16]. In contrast to our study, there was no age-related pattern to pain among older adults and pain prevalence remained similar across the age groups [17]. The differences in the findings may possibly due to the diversity and comorbid conditions of the older people. Ferrell et al. study was nursing home based and it can be assumed that health status of the elderly samples tended to be poorer and pain would likely be higher than that lived at home and Lansbury had included elders having age 65 years and over. Most cross-sectional epidemiological studies have shown that the overall prevalence of pain increases with advancing age. However, it is also apparent that the agerelated increase in overall pain prevalence does not continue beyond the seventh decade of life. The reasons for maintaining a steady frequency of pain report beyond that time remain largely unknown [18].

When pain was worst, at that time extreme pain was reported by $13.1 \%$ respondents, $54.1 \%$ were ranked moderate pain, $31.2 \%$ were ranked severe pain and only $1.6 \%$ had expressed mild pain. In a similar study conducted by Yu HY et al. among Taiwanese community older people, revealed that $10.9 \%$ subjects had mild, $48.9 \%$ had moderate and $40.2 \%$ had severe type of pain when the pain was at its worst time [15]. The mean intensity of pain was found $6.67 \pm 1.85$ which indicate severe pain was prevalent in our sample when pain was worst in its kind. This finding is, however, like the study previously conducted in Taiwan that means severe pain was prevalent in Taiwanese older people too. These data also revealed that the largest proportion of this sample

\begin{tabular}{|c|c|c|c|c|c|c|c|c|}
\hline Activities & $\begin{array}{c}\text { Doesn't interfere } \\
\text { (0) }\end{array}$ & $\begin{array}{l}\text { Slight interfere } \\
(1-3)\end{array}$ & $\begin{array}{c}\text { Moderate } \\
\text { interfere (4-6) }\end{array}$ & $\begin{array}{c}\text { Severe interfere } \\
(7-9)\end{array}$ & $\begin{array}{c}\text { Complete } \\
\text { interfere (10) }\end{array}$ & $\begin{array}{l}\text { Mean interference } \\
\quad \text { (mean, SD) }\end{array}$ & $\begin{array}{l}\text { Correlation } \\
\text { coefficient (r) }\end{array}$ & $p$ value \\
\hline General Activities & $28(45.9 \%)$ & 24 (39.3\%) & $5(8.2 \%)$ & $3(4.9 \%)$ & $1(1.6 \%)$ & $1.59 \pm 2.16$ & 0.228 & 0.077 \\
\hline Mood & $12(19.7 \%)$ & $21(34.4 \%)$ & $18(29.5 \%)$ & $7(11.5 \%)$ & $3(4.9 \%)$ & $3.44 \pm 2.76$ & 0.377 & 0.003 \\
\hline Walking ability & $22(36.1 \%)$ & $24(39.3 \%)$ & $14(23.0 \%)$ & 0 & $1(1.6 \%)$ & $2.08 \pm 2.11$ & 0.130 & 0.319 \\
\hline Normal work & $38(62.3 \%)$ & $22(36.1 \%)$ & $1(1.6 \%)$ & 0 & 0 & $0.77 \pm 1.16$ & 0.218 & 0.092 \\
\hline $\begin{array}{l}\text { Relation with } \\
\text { others }\end{array}$ & $51(83.6 \%)$ & $9(14.8 \%)$ & $1(1.6 \%)$ & 0 & 0 & $0.39 \pm 1.04$ & 0.244 & 0.058 \\
\hline Sleep & $15(24.6 \%)$ & $21(34.4 \%)$ & $19(31.1 \%)$ & $5(8.2 \%)$ & $1(1.6 \%)$ & $3.08 \pm 2.60$ & 0.621 & $<0.001$ \\
\hline Enjoyment of life & 45 (73.8\%) & $13(21.3 \%)$ & $3(4.9 \%)$ & 0 & 0 & $0.64 \pm 1.28$ & 0.463 & $<0.001$ \\
\hline
\end{tabular}

Table 3: Interference of pain on daily activities $(n=61)$. 
suffered from severe pain due to multiple diseases and the prevalence rate of fracture was higher [19]. Some other studies also indicated that chronic pain increases with age [7] and such chronic pain in older persons is known to be associated with the appearance of illnesses and other health conditions $[20,21]$. In the current study, the presence of any disease among elderly is more likely to experience persistent pain than who do not have any chronic diseases and most of the elderly who met any kind of injury in their life were also suffering more from the pain which is in accordance with previous research where the pain among older adults was significantly associated with the presence of other comorbid illnesses [22]. Some of them also perceived that their pain was due to the presence of disease and/or injury in their life that also supports to our findings. There are a number of factors that may explain the poor pain outcomes experienced by elderly, including the severity of the diseases and injuries in the sample, long duration of pain and inadequate pain relief.

To obtain the pain characteristic perceiving by the elderly sample during pain, respondents were asked to select the word they felt best described their pain. In the study sample, the elderly mainly expressed their pain as burning, cramping and dull in nature. Among the study sample, burning type pain was expressed by most of the male respondents but cramping type pain was mostly reported by female respondents. Regarding the characteristics of pain, most of the older people in Yu HY et al.s study reported that their pain was an ache $(62.7 \%)$ or cramps $(12.7 \%)$ and that it was caused by diseases including osteoporosis (20.0\%) and unidentified illnesses (17.9\%) [15]. The reason of burning complaints in our study may be due to that majority had the chronic gastritis disease. Among all, $32.8 \%$ of the respondents had pain in their legs having especially joint problem followed by $14.8 \%$ respondents were feeling pain in spinal/waist region, $13.1 \%$ had pain in any part of their hands, $11.5 \%$ were feeling pain on abdomen, $8.2 \%$ had chest pain and respondents feeling pain in head, mouth and neck were in equal 6.6 percentages each. This result is consistent with the reports of Picker institute Europe 2007 where it was mentioned that the most widely cited areas of pain were the legs (including knees), followed by back, arms and shoulders [7,23]. In a study, over $60 \%$ of the participants reported experiencing pain only occasionally, and morning and evening was the time of the day when the pain experience was worst [8], but our study identified evening and night are the time of experiencing pain. The difference in time of pain might be due to time of taking pain medication by the respondents.

In our study, the highest interference by pain was found on mood and sleep. The overall mean interference of pain on activities of older people in this study was slight and pain intensity was correlated with activities such as sleep, mood and enjoyment of life. The result of present study seems similar to previous studies in some extents that the mean interference was slight $(2.90 \pm 2.55)$. Chronic pain had mostly affected older people's activities of walking, mood and normal work. Enjoyments of life, relationship with others, sleeping and general activities of daily living were least influenced [14].

Only the sleep interference was found higher instead of normal work in our study. The finding is consistent with the study by Eslami et al. where pain grade was found to be associated with sleep disturbance after adjusting the demographic variables [24]. Neubauer DN in his study also found that pain and discomfort delay sleep onset and shorten the duration of sleep [25]. The aging process likely to plays an important role for higher interference in sleep of elders. Another reasonable explanation may relate to the pain that is prevailing from long duration of time and negatively affecting their mood. Picker Institute in Europe also identified that pain is responsible for depression and irritability among many residents, disturbing their sleep, restricting mobility and limiting their ability to take part in communal activities [23]. One study by Boerlage et al. had also identified the pain as a significant predictor that interfere the mood and general activity among the Dutch people [26]. The results of this study predicted an important issue that pain was a problem of great concern for the individuals in that population, specially increase of pain severity have the greater impact on other activities like mood, sleep, enjoyment of life. This may suggest proper assessment and management of pain could possibly assist in alleviating sleep disturbance and mood interference and ultimately decrease interference in daily activities.

\section{Conclusion}

In conclusion, this study revealed that the chronic physical pain is undeniably a common problem among the older people. Their pain experiences interfered considerably to their daily activities. Pain had significantly affecting in their mood and sleeping pattern as well as enjoyment of life. Those who were experiencing pain were mainly due to the presence of some diseases or injuries in their lives. The results of this study emphasize the importance of pain assessment and management to improve the mood and living condition of the elderly people. Healthcare provider can play an important role in managing pain by providing psychological consultation as well as practicing pain assessment regularly in this population. Besides it will be worthwhile if we conduct some community education programme to the older people regarding self-care strategies to manage their pain as well as to their family members regarding need of better care for making their life more comfortable.

\section{References}

1. World Health Organization, Regional office for South-East Asia (2004) Health of the elderly in South-East Asia, a profile, New Delhi, India.

2. Geriatric Center Nepal (2010) Status report on elderly people in Nepa on health, nutrition and social status focusing on research needs. MoHP Kathmandu, Nepal.

3. National Planning Commission Secretariat Central Bureau of Statistics (2002) Population monograph. p. 1.

4. National Planning Commission Secretariat (2012) Central Bureau of Statistics, National population and housing census. p. 1.

5. Ferrell BA, Ferrell BR, Rivera L, Fann (1995) Pain in cognitively impaired nursing home patients. J Pain Symptom Manag 10: 591-598.

6. Helme RD, Gibson SJ (2001) The epidemiology of pain in elderly people. Clin Geriatr Med 17: 417-31.

7. Crook J, Rideout E, Browne G (1984) The prevalence of pain complaints in a general population. Pain 18: 299-314.

8. Brown ST, Kirkpatrick MK, Swanson MS, MCKenzie IL (2011) Pain experience of the elderly. Pain Manag Nurs 12: 190-196.

9. Jakobsson $U$ (2004) Pain and quality of life among older people: focusing on rheumatoid arthritis and osteoarthritis. In: Columbus F (ed). Focus on Arthritis Research. Nova Science Publisher Inc., New Yoek, USA. pp. 89-113.

10. Pickering G (2004) Frail elderly, nutritional status and drugs. Arch Geronto Geriatr 38: 174-180.

11. Yasemin KY, Uyar M, Fadillioglu C (2005) Cancer pain and its influence on quality of life. J Turk Soc Algology 17: 17-22.

12. Anita CA, LaRae IH (1999) Pain, cancer and older adults. Geriatr Nurs 20 241-247.

13. Cleeland CS, Gonin R, Hatfield AK, Edminsoon JH, Blum RH, et al. (1994) Pain and its treatment in outpatients with metastatic cancer. The New England J Med 592-596.

14. Lansbury G (2000) Chronic pain management: A qualitative study of elderly persons' preferred coping strategies and barriers to management. Disabi Rehabil 22: 2-14. 
Citation: Subedi SN (2017) Pattern of Pain and its Interference on Activities of Daily Life among Older Adults in Bharatpur Municipality, Chitwan, Nepal. J Gerontol Geriatr Res 6: 445. doi:10.4172/2167-7182.1000445

15. Yu HY, Tang FI, Kuo BI, Yu S (2006) Prevalence, interference, and risk factors for chronic pain among Taiwanese community older people. Pain Manag Nurs 7: 2-11.

16. Francesco L, Graziano O, Matteo C, Giovanni G, Knight S, et al. (2001) Pain management in frail, community-living elderly patients. Arch Inter Med 161: 2721-2724.

17. Patel KV, Guuralnik JM, Dansie EJ, Turk DC (2013) Prevalence and impact of pain among older adults in the United States: Findings from the 2011 National Health Survey and aging trends study. Pain 154: 2649-2657.

18. Helme RD, Gibson SJ (1999) Epidemiology of pain- pain in older people. National Ageing Research Institute. Australia: IASP Press 17: 417-431.

19. Tsai YF, Tsai HH, Lai YH, Chu TL (2004) Pain prevalence, experiences and management strategies among the elderly in Taiwanese nursing homes. J Pain Symptom Manage 28: 579-584.

20. Mitchell C (2001) Assessment and management of chronic pain in elderly people. Br J Nurs 10: 296-304.
21. Priano L, Gasco MR, Mauro A (2006) Transdermal treatment options for neurological disorders: Impact on the elderly. Drugs Aging 23: 357-375.

22. Satghare P, Chong SA, Vaingakar J, Picco L, Abdin E, et al. (2016) Prevalence and correlates of pain in people aged 60 years and above in Singapore: Results from the WiSE study. Pain Research Manag.

23. Cairncross L, Magee H, Askham J (2007) A hidden problem: pain in older people, A qualitative study. Picker Institute Europe. UK.

24. Eslami V, Zimmerman ME, Grewal T, Katz M, Lipton RB (2016) Pain grade and sleep disturbance in older adults: Evaluation the role of pain, and stress for depressed and non-depressed individuals. Int J Geriatr Psychiatry 31: 450-457.

25. Neubauer DN (1999) Sleep problems in the elderly. Am Fam Physician 59: 2551-2558.

26. Boerlage AA, Dijk MV, Stronks DL, Wit R, Rijt CD (2008) Pain prevalence and characteristics in three Dutch residential homes. Eur J Pain 12: 910-916. 